\title{
PENERAPAN ALGORITMA A* UNTUK MENCARI JARAK TERDEKAT TEMPAT WISAT KOTA MALANG RAYA
}

\author{
Mukhlis $^{1}$, Mira Orisa ${ }^{2}$, F.X Ariwibisono ${ }^{3}$ \\ Program Studi Teknik Informatika S1, Fakultas Teknologi Industri \\ Institut Teknologi Nasional Malang, Jalan Raya Karanglo km 2 Malang, Indonesia \\ Mkhlis040897@gmail.com
}

\begin{abstract}
ABSTRAK
Pariwisata Malang Raya terdiri dari tempat-tempat wisata yang ada di daerah Kota Malang, Kabupaten Malang dan Kota Batu. Setiap wilayah administrative itu memiliki ciri khas daerah wisatanya masing-masing. Kota Malang menjadi kota terbesar kedua di Jawa Timur setelah Kota Surabaya. kini banyak dikeluhkan warganya seperti kemacetan dan kesemrawutan lalu lintas di karenakan banyaknya kendaraan dari luar kota yang berlibur ke tempat wisata-wisata di Kota Malang. Oleh sebab itu waktu dan jarak tempuh ke destinasi wisata pun sangat penting untuk kenyaman perjalanan wisatawan.

Kebutuhan masyarakat terhadap efisiensi jarak tempuh ke suatu tempat tujuan wisata berdasarkan jarak tempuh terdekat dapat diselesaikan dengan pembuatan aplikasi ini. Pada aplikasi ini menggunakan algoritma A*. Penerapan algoritma $A^{*}$ bertujuan untuk mencari jalur dengan jarak terdekat. Pendekatan yang digunakan adalah pendekatan heuristik untuk memperkirakan jalur terbaik dari titik awal ke titik akhir. Pendekatan ini memberikan peringkat ke tiap titik yang dilalui dari titik awal ke titik tujuan. Selain itu Google Maps digunakan untuk menampilkan hasil dari perhitungan jarak.

Hasil dari pengujian fungsional menyatakan aplikasi berjalan sesuai dengan rancangan. Hasil pengujian penerapan metode $\mathrm{A}^{*}$ pada aplikasi ini sudah sesuai dengan perhitungan manual algoritma $\mathrm{A}^{*}$. Untuk hasil kuisioner pengguna menyatakan untuk tampilan aplikasi 50\% menyatakan menarik, 90\% menyatakan kemudahan penggunaan aplikasi, 70\% menyatakan aplikasi sesuai fungsinya yaitu mencari jarak terdekat, dan $90 \%$ menyatakan fitur berjalan baik.
\end{abstract}

Kata kunci : Algoritma A*,Pariwisata,Jarak terdekat, Malang, Kota Batu

\section{PENDAHULUAN}

\subsection{Latar Belakang}

Pemerintah Kota Malang dan kota Batu selalu berbenah diri untuk menjadi kota destinasi wisata yang bukan hanya sebatas wisata berbasis peninggalan bersejarah dan kuliner saja tetapi juga menghadirkan lebih banyak tempat-tempat wisata yang baru seperti yang disampaikan oleh Sutiaji selaku Wali Kota Malang di Merdeka.com. pemerintahan Kota Malang menargetkan pada tahun 2019 ini sebanyak 150.000 kunjungan wisatawan. Sedangkan Kabupaten Malang yang memiliki luasan yang paling besar dan juga memiliki potensi pariwisata yang besar. Kota Batu juga memiliki potensi besar karena keindahaan alamnya.

Kota Malang menjadi kota terbesar kedua di Jawa Timur setelah Kota Surabaya. Dengan demikian banyak warga yang mengeluh dengan kemacetan lalulintas di Kota Malang di karenakan banyaknya kendaraan dari luar kota yang berlibur ke tempat wisata-wisata di Kota Malang. Sebegitu besarnya daya tarik Kota Malang sehingga mampu menarik massa begitu besar tidak hanya dari dalam negri tapi juga luar negri. Oleh sebab itu waktu dan jarak tempuh ke destinasi wisata pun sangat penting untuk kenyaman perjalanan wisatawan.

Pada website pemerintahan Kota malang belum tersedia sistem informasi geografis tentang destinasi wisata. Dan melihat banyaknya jalan raya dan jalan alternative di Malang raya sehingga melatarbelakangi dibangun sistem informasi geografis untuk pencarian jarak terdekat wisatawan dengan destinasi wisata demi kenyaman perjalanan wisata. Sistem ini akan dibangun berbasis website dan menerapkan Algoritma A* sebagai perhitungan untuk menentukan jarak terdekat. Karena Algoritma A* menggunakan estimasi jarak terdekat untuk mencapai tujuan (goal) dan memiliki nilai heuristik yang digunakan sebagai dasar pertimbangan.

\subsection{Rumusan Masalah}

Dari latar belakang masalah diatas, maka rumusan masalah yang akan dibahas pada penelitian ini antara lain:

1. Bagaimana membangun sistem informasi geografis untuk menentukan jarak terdekat bagi para wisatawan ke lokasi wisata?

2. Bagaimana menerapkan Algoritma $A^{*}$ dalam melakukan penenetuan jarak terdekat untuk para wisatawan di Malang Raya ?

\subsection{Batasan Masalah}

Adapun batasan masalah pada penelitian ini sebagai berikut:

1. Sistem ini menggunakan metode Algoritma $A^{*}$ dalam penentuan jarak terdekat. 
2. Sistem ini memberikan alternatif keputusan terbaik berdasarkan parameter berupa jarak dan titik koordinat yaitu hanya satu rute yang akan menjadi output sistem.

3. Data yang diambil adalah 10 tempat wisata di Kota Malang, 10 tempat wisata di kota Batu, dan 10 tempat wisata di Kabupaten Malang.

4. Sistem ini dirancang bagi para wisatawan di Malang Raya.

\subsection{Tujuan}

Tujuan dari pembuatan aplikasi ini adalah sebagai berikut:

1. Merancang dan membangun sebuah sistem informasi yang membantu para wisatawan di Kota Malang untuk menimati tempat wisata yang di inginkan.

2. Mampu menerapkan Algoritma A* untuk sebuah sistem informasi penentuan jarak terdekat.

\section{TINJAUAN PUSTAKA}

\subsection{Sistem Informasi Geografis}

Sistem Informasi Geografis (SIG) merupakan suatu sistem yang dirancang untuk menangani pengolahan dan pengelolan data informasi geografis berupa peta digital. Sering perkembangan zaman dan pesatnya perkembangan teknologi pada saat ini, menjadikan SIG sangat diminati oleh orang banyak dengan kecanggihan teknologi yang dimiliki ${ }^{[13]}$. Teknologi SIG mengintergrasikan operasi - operasi seperti database, query dan analisa statistik, kemampuan inilah yang menjadikan SIG beda dari sistem informasi lainnya yang menjadikan SIG sangat berguna untuk merancang strategi dan memprediksi yang terjadi. ${ }^{[11]}$

\subsection{Algoritma $A^{*}$}

Algoritma $A^{*}$ merupakan salah satu algoritma penentuan jarak terdekat. Algortima $A^{*}$ sangat baik sebagai solusi mencari jarak rute tercepat yang akan di tempuh dari titik awal sampai ke titik tujuan. Algoritma A* menggunakan nilai heuristik yang akan digunakan sebagai dasar pertimbangan.

Fungsi heuristik :

$$
\begin{gathered}
\text { Dx }=(\text { node } \mathrm{x}-\text { goal } \mathrm{x}) \\
\text { Dy }=(\text { node } \mathrm{y}-\text { goal } \mathrm{y}) \\
\text { Return } \mathrm{D} *(\mathrm{Dx}+\mathrm{Dy})
\end{gathered}
$$

Rumus diatas digunakan karena aplikasi ini menggunakan fungsi heuristic manhattan distance. Secara umum dapat dijelaskan sebagai berikut:

1. Masukkan titik awal.

2. Setelah itu masuk ke looping, sebagai berikut:

a. Cari titik dengan nilai jarak yang terkecil

b. Pilih titik yang nilainya terkecil (yang akan dilewati)

c. Bandingkan setiap titik tetangga dan pilih yang bernilai terkecil (yang akan dilewati), begitu seterusnya sampai ke titik tujuan d. Looping berhenti. ${ }^{[7]}$

\section{METODE PENELITIAN}

3.1 Blok Diagram Sistem

Adapun blok diagram dari sistem ini seperti pada Gambar 1 berikut:

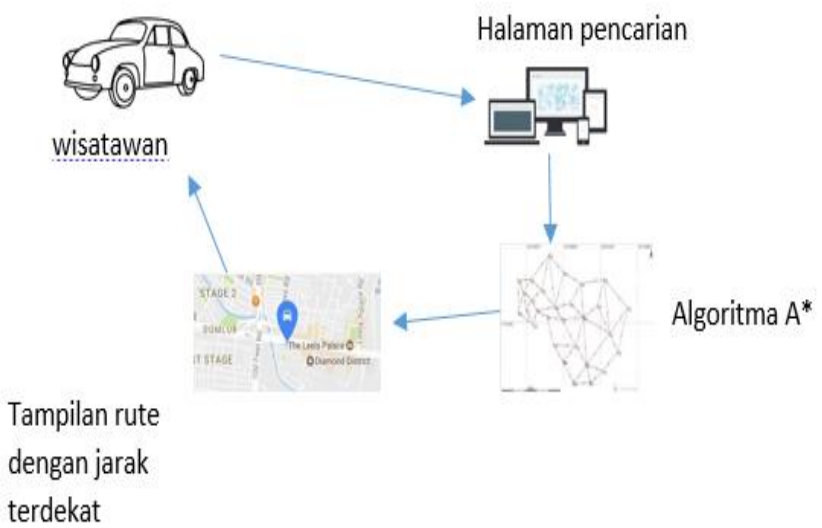

Gambar 1. Blok diagram sistem

Pada blok diagram perancangan sistem penentuan jarak terdekat menggunakan metode Algoritma A* ditunjukkan pada Gambar 1. Dari blok diagram pada Gambar 1 menunjukkan bahwa ketika wisatawan membuka website GIS kemudian memasukkan data jarak antara titik awal dan titik tujuan. Data masukakan tersebut akan dimodelkan dalam sebuah persamaan sehingga dapat dilakukkan proses perhitungan. Proses perhitungan dilakukan menggunakan Algoritma $A^{*}$ dengan bahasa pemrograman web. Kemudian hasil akan ditampilkan ke website GIS berupa Map yang menunjukkan Jarak terdekat yang dapat dilewati para wisatawan menuju tempat wisata di Malang Raya.

\subsection{Data Flow Diagram Level 0}

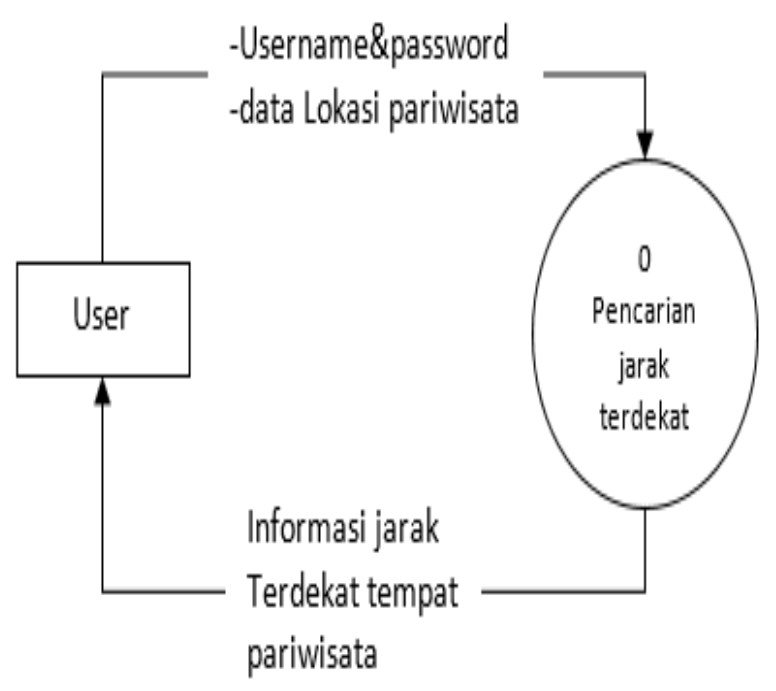

Gambar 2. DFD level 0 
DFD Level 0 menjelaskan bahwa ada 1 pelaku yang terdapat di dalam aplikasi yaitu admin. Admin yang bertugas untuk mengelola data yang ada di aplikasi tersebut.

\section{Data Flow Diagram Level 1}

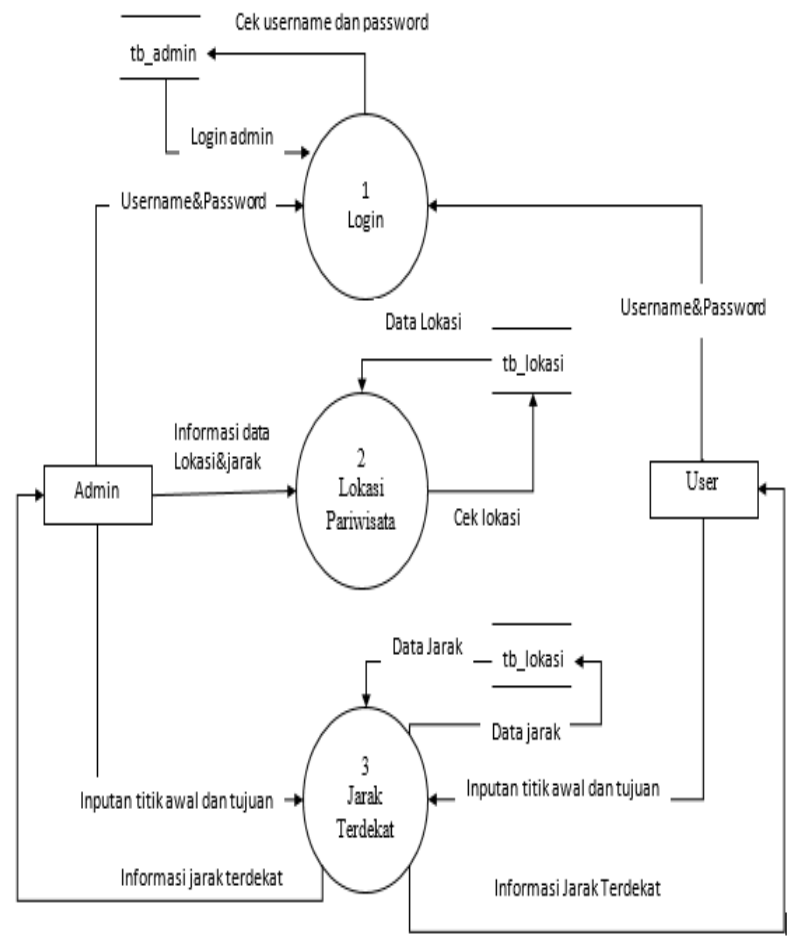

Gambar 3. DFD level 1

DFD level 1 pada Gambar 3 menyatakan bahwa penentuan jarak terdekat menggunakan Algoritma A* ini terdapat 3 proses yaitu proses 1 login, proses 2 lokasi pariwisata, proses 3 perhitungan jarak terdekat. Setiap proses di jelaskan dengan DFD level 1 secara detail.

\subsection{Flowchart Sistem}

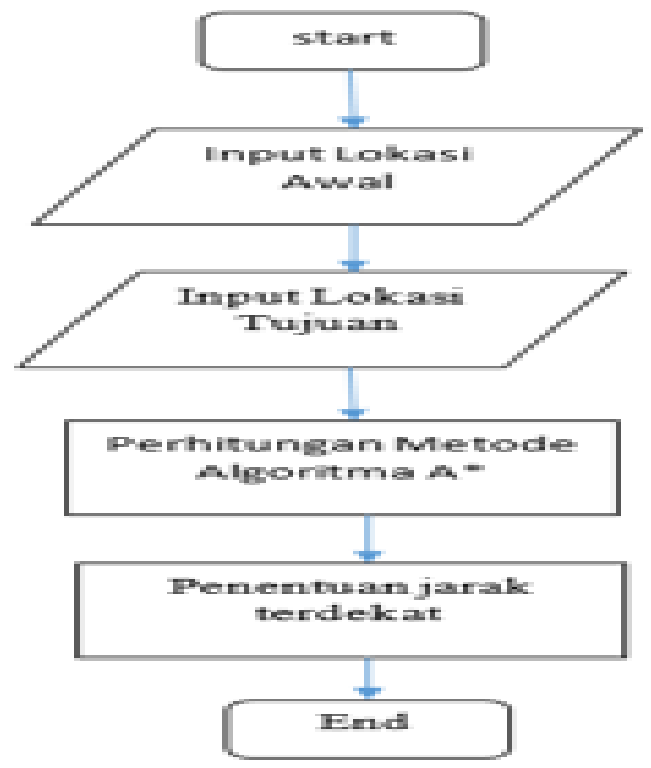

Gambar 4. Flowchart sistem

Sistem ini dimulai dengan menginputkan data lokasi, kemudian diberikan input lokasi tujuan. Setelah itu sistem akan melakukan perhitungan jarak menggunakan metode Algoritma $A^{*}$. Proses perhitungan itu sendiri menghasilkan jalur yang akan dilewati sebagai jarak terdekat bagi para wisatawan di kota Malang dan sekitarnya.

\subsection{Flowchart Metode Algoritma A*}

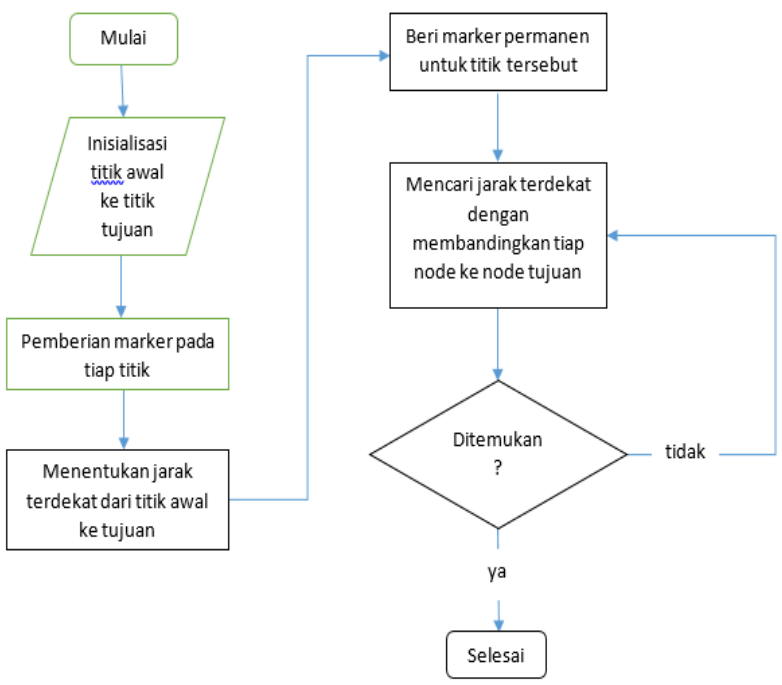

Gambar 5. Flowchart metode Algoritma A*

Metode Algortima A*dimulai dari menginisialisasikan antara titik awal ke titik tujuan dan tiap-tiap titik. Setelah itu menentukan jarak dengan cara menghitung dan membandingkan tiaptiap node sehingga ditemukan jarak terdekat, setelah ditemukan maka diberikan marker permanen pada titik tersebut. Setelah diberikan marker maka akan dibandingkan lagi untuk mencari jarak terdekat menuju titik tujuan, maka akan ditemukan jalur yang dilewati.

\section{HASIL DAN PEMBAHASAN \\ 4.1 Halaman Login}




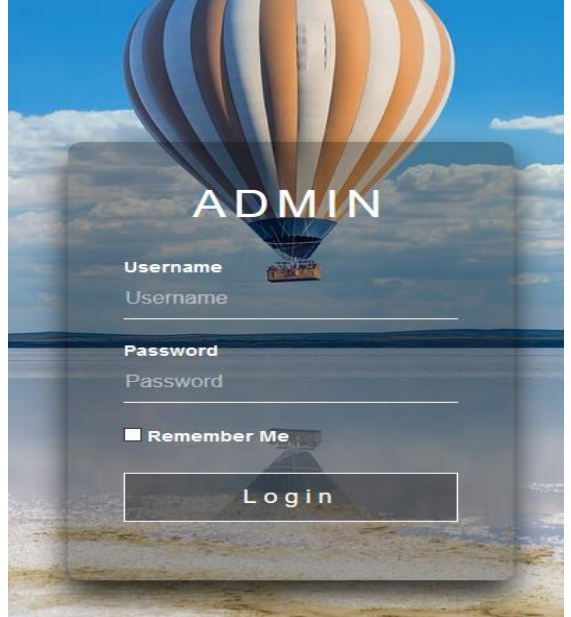

Gambar 6. Halaman login

Halaman login admin merupakan halaman yang ada pertama kali saat admin membuka aplikasi. Pada halaman login mengharuskan admin harus menginputkan username dan password agar bisa melanjutkan ke halaman utama (home) dan admin mempunyai hak penuh untuk aplikasi ini.

\subsection{Halaman Home}

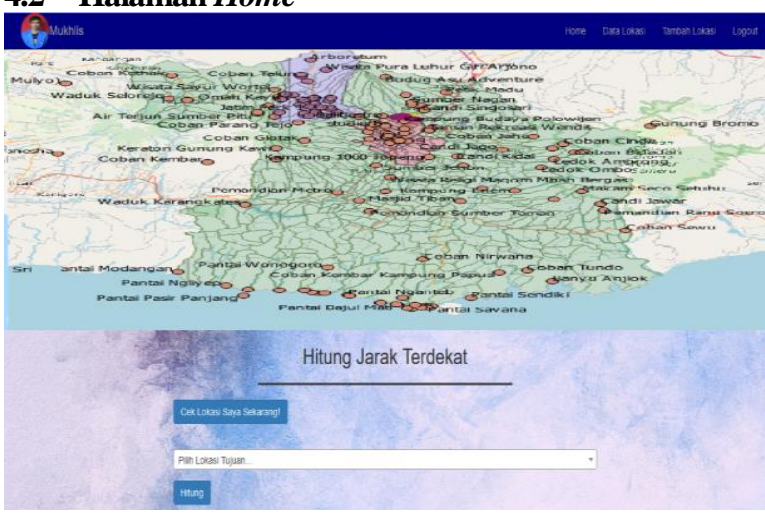

Gambar 7. Halaman Home

Pada gambar 7 merupakan halaman utama dari aplikasi pencarian jarak terdekat wisata di Kota Malang Raya. halaman utama (home) terdapat peta lokasi pariwisata di Kota Malang Raya yang di gunakan untuk mencari jarak terdekat yang dapat di tempuh para wisatawan dari lokasi awal menuju lokasi tujuan wisata berikutnya. Lokasi awal menggunakan tombol agar mempermudah untuk melacak lokasi yang terkini dan tujuan dapat di pilih pada combobox yang telah di sediakan.

\subsection{Halaman Data Lokasi}

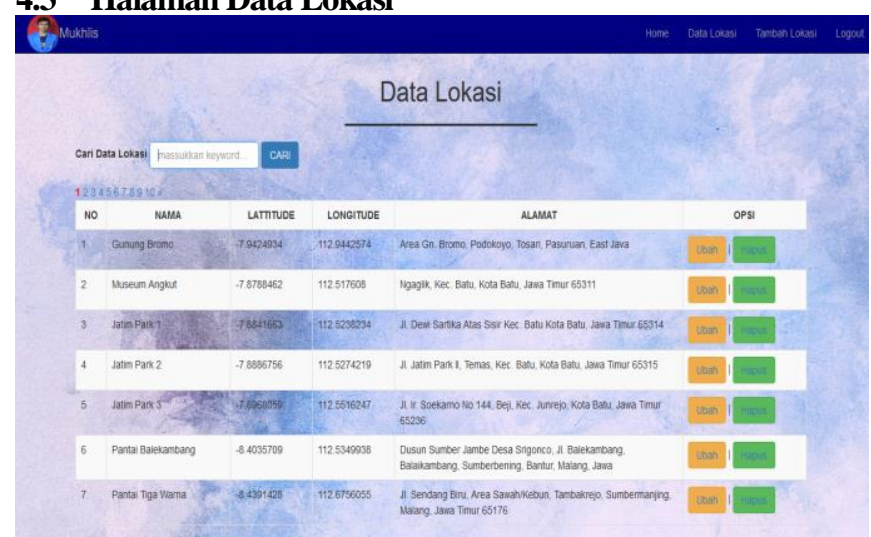

Gambar 8. Halaman Data Lokasi

Pada gambar 8 merupakan halaman data lokasi wisata yang ada di Kota Malang Raya. Data lokasi tersebut digunakan untuk mempermudah menentukan destinasi wisata yang ingin dikunjungi di Kota Malang Raya. Admin juga bisa mengubah dan menghapus data lokasi wisata di kota malang raya.

\subsection{Halaman Tambah Lokasi}

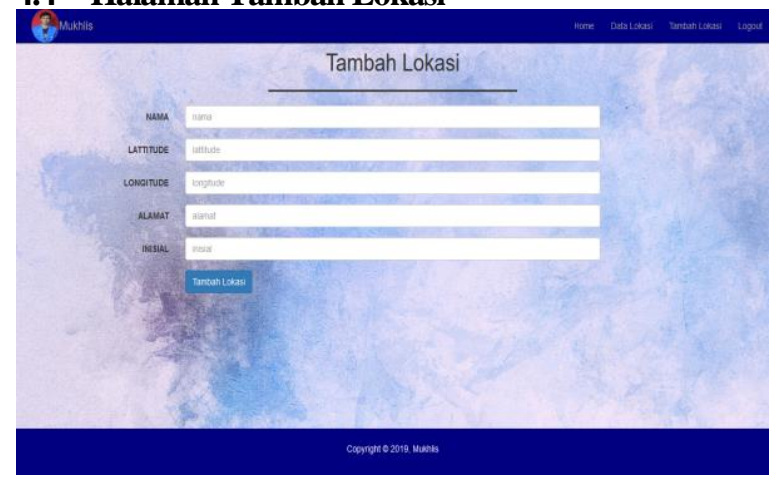

Gambar 9. Halaman Tambah Lokasi

Pada gambar 9 merupakan halaman tambah lokasi yang digunakan untuk menambahkan lokasi wisata yang belum terdapat di peta di halaman utama (home), agar mempermudahkan pengguna (user) mencari jarak terdekat yang di tempuh ke lokasi wisata yang di pilih. 


\subsection{Halaman Hasil Penentuan Jarak Terdekat}

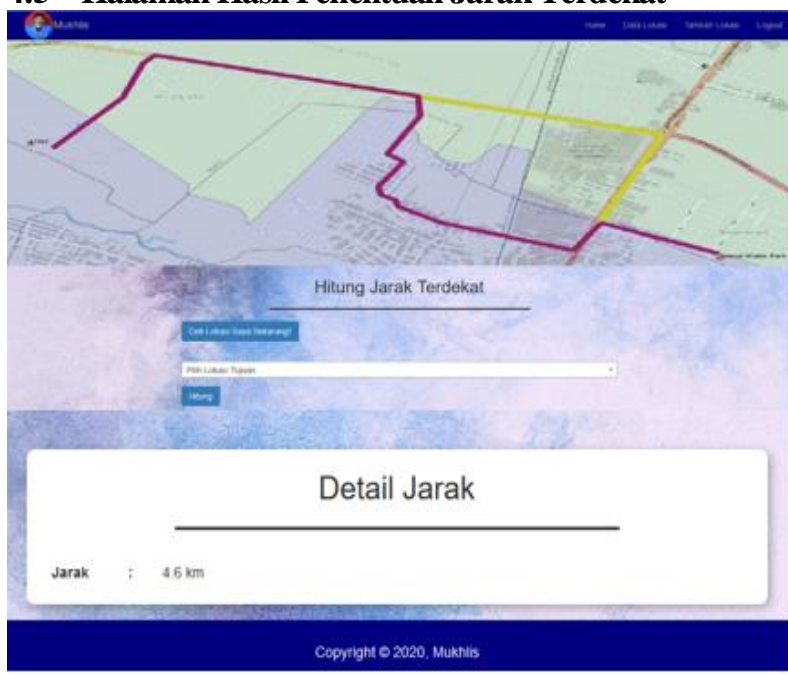

Gambar 10. Halaman hasil

Pada Gambar 10 merupakan hasil penentuan jarak terdekat dari lokasi awal si pengguna (user) ke tempat wisata yang di tuju. Hasil penentuan jarak terdekat menampilkan rute yang tercepat untuk di tempuh oleh si pengguna (user).

\subsection{Pengujian Algoritma A Star (A*)}

Penjelasan analisis perhitungan dari algoritma A Star (A*) untuk scenario 1 misalkan menentukan tujuan tempat wisata Hawai jika user berada di ITN kampus 2. Hal pertama yang akan dilakukan user menentukan tempat asal. Dari tabel tempat diambil nilai Longitude (x) dan Latitude (y). Misalkan ditentukan tempat asal adalah ITN kampus 2 dengan nilai Longitude $(\mathrm{x})=112.6320693$ dan Latitude $(\mathrm{y})=$ -7.9165401 Kemudian menentukan tempat tujuan Hawai Longitude $(\mathrm{x})=112.6570293$ dan Latitude $(\mathrm{y})$ -7.923639. Selain itu diketahui bahwa terdapat 2 rute yang bisa dilalui user untuk sampai ke tempat tujuan. Kemudian dilakukan perhitungan heuristic untuk menentukan rute mana yang paling dekat. Rumus Heuristic ecludian distance:

$$
d(x, y)=\sqrt{ }(x 1-y 1)^{2}+(x 2-y 2)^{2}
$$

Hasil dari perhitungan adalah :

Tabel 1 Heuristic Ecludian Distance

\begin{tabular}{|l|l|}
\hline \multicolumn{1}{|c|}{ Rute } & \multicolumn{1}{c|}{ Heuristic ecludian distance } \\
\hline Rute 1 & $\begin{array}{l}25.8-16.2-10-3.4-8-10 \\
-4-8\end{array}$ \\
\hline Rute 2 & $25.8-16.2-12-16-8$ \\
\hline
\end{tabular}

Maka menurut hasil perhitungan algoritma $\mathrm{A}^{*}$ didapatlah rute 1 untuk di tempuh oleh user menuju ke tempat tujuan. Rute 1 memiliki nilai antar node yang lebih pendek dibandingkan rute 2. Pada saat persimpangan Algoritma $A^{*}$ memilih node yang memiliki nilai paling kecil untuk rute yang akan dilewati selanjutnya maka pada 2 persimpangan yang ditemui saat user akan menuju hawai yaitu persimpangan 1 memiliki nilai nodenya 10 dan persimpangan 2 memiliki nilai node 12, sehingga dipilihlah rute yang akan ditempuh selanjutnya yaitu persimpangan yang memiliki nilai node terkecil yaitu 10. Hal tersebut dapat terlihat pada Gambar 11

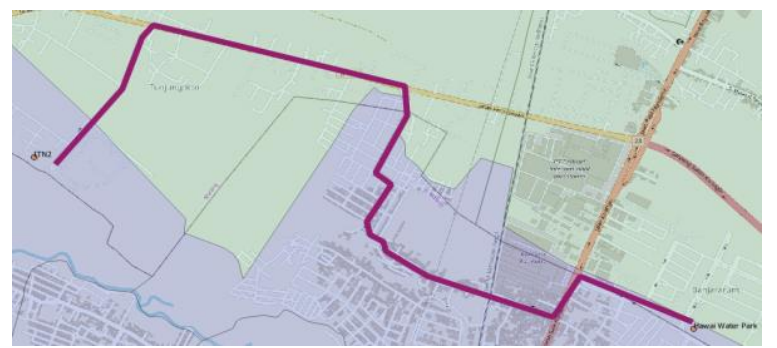

Gambar 11. Rute Jalur 1

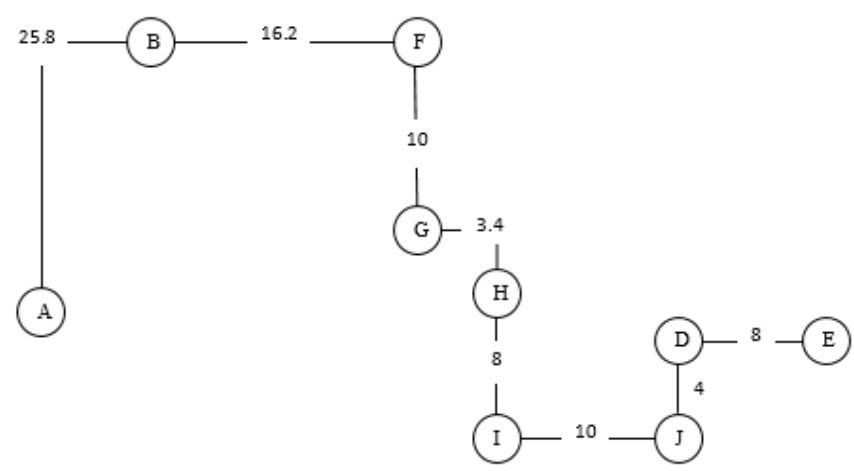

Gambar 12. Graph Rute Jalur 1

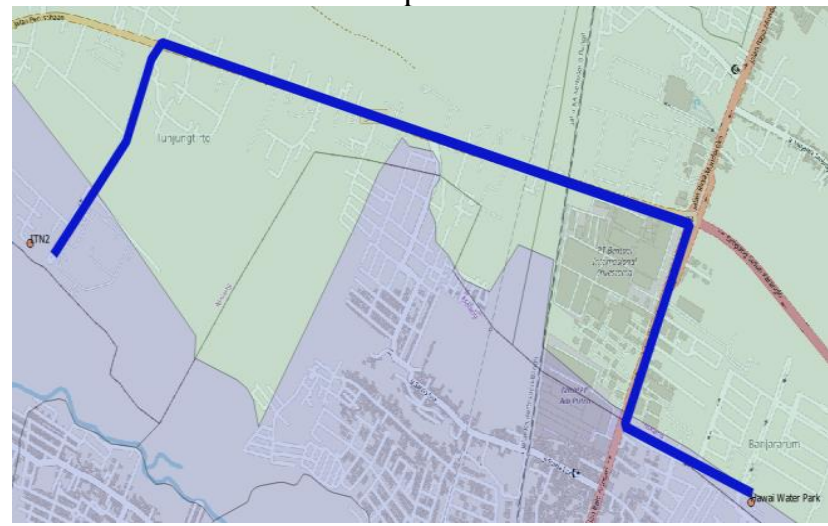

Gambar 13. Rute Jalur 2

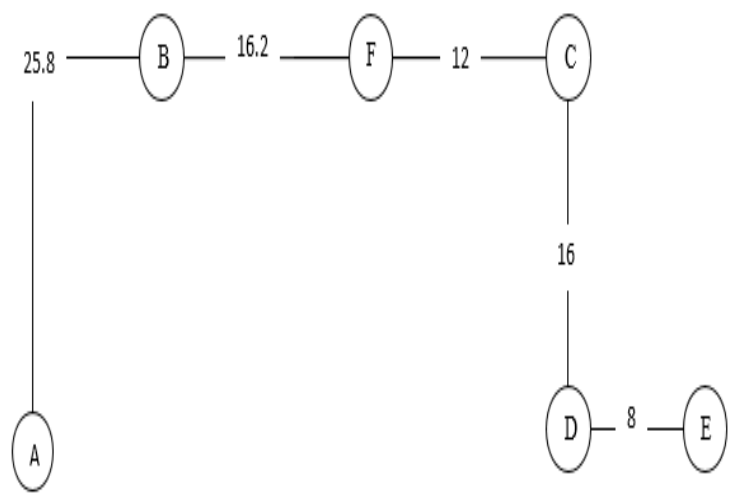

Gambar 14. Graph Rute Jalur 2

\subsection{Pengujian Fungsional Aplikasi}

Pengujian fungsional merupakan cara untuk mengetahui apakah fitur-fitur dari aplikasi yang tersedia dapat berjalan tanpa ada kendala yang 
membuat sistem tidak berfungsi dengan baik. Dalam tahapan pengujian fungsional ini di mulai dari halaman registrasi hingga selesai.

Hasil pengujian fungsional fitur-fitur aplikasi dapat dilihat pada tabel diatas. Setelah dilakukan pengujian terhadap 2 browser tersebut, semua fungsi dari sistem berjalan sesuai dengan yang diinginkan.

Tabel.2.Pengujian Fungsional

\begin{tabular}{|c|c|c|c|}
\hline \multirow{2}{*}{$\mathrm{N}_{0}$} & \multirow{2}{*}{ Fungsi } & \multicolumn{2}{|c|}{ Browser } \\
\hline & & Mozzila & Chrome \\
\hline 1 & $\begin{array}{l}\text { Registrasi: masukkan } \\
\text { username, password, dan } \\
\text { konfirmasi password. }\end{array}$ & S & $S$ \\
\hline 2 & $\begin{array}{l}\text { Login: masukkan username } \\
\text { dan password. }\end{array}$ & $S$ & $\mathrm{~S}$ \\
\hline 3 & $\begin{array}{l}\text { Halaman utama: admin } \\
\text { dapat melihat peta lokasi } \\
\text { wisata dan titik lokasi. }\end{array}$ & S & $S$ \\
\hline 4 & $\begin{array}{l}\text { Data lokasi: admin dapat } \\
\text { melihat data lokasi tempat } \\
\text { wisata di Malang Raya. }\end{array}$ & S & $S$ \\
\hline 5 & $\begin{array}{l}\text { Tambah Lokasi: admin } \\
\text { dapat menambahkan lokasi } \\
\text { yang belum ada di peta. }\end{array}$ & S & $S$ \\
\hline 6 & $\begin{array}{l}\text { Admin dapat melakukan } \\
\text { pencarian jarak terdekat ke } \\
\text { tempat wisata dari titik awal } \\
\text { admin berada. }\end{array}$ & S & S \\
\hline
\end{tabular}

\section{KESIMPULAN DAN SARAN}

\subsection{Kesimpulan}

Setelah melakukan pengujian pada aplikasi penentuan jarak terdekat dengan menggunakan Algoritma A*, maka dapat di Tarik kesimpulan sebagai berikut:

1. Pada pengujian fungsional yang dilakukan dapat di simpulkan bahwa aplikasi penentuan jarak terdekat tempat wisata di Kota Malang Raya dengan menggunakan Algortima $A^{*}$ dapat berjalan sesuai dengan yang di inginkan pada beberapa browser seperti Mozzila dan Chrome.

2. Untuk hasil kuisioner pengguna menyatakan untuk tampilan aplikasi 50\% menyatakan menarik, $90 \%$ menyatakan kemudahan penggunaan aplikasi, $70 \%$ menyatakan aplikasi sesuai fungsinya yaitu mencari jarak terdekat, dan 90\% menyatakan fitur berjalan baik.

3. Dari 10 kasus yang diuji pada aplikasi menyatakan bahwa aplikasi telah berhasil berjalan sesuai dengan perhitungan manual dari algoritma A*.

\subsection{Saran}

Pada rancang bangun aplikasi penentuan jarak terdekat dengan menggunakan Algoritma $\mathrm{A}^{*}$ terdapat kelebihan dan kekurangan, oleh karena itu saran untuk memperbaiki sistem ini.

Berikut ini adalah saran dari penelitian yang telah dilakukan:

1. Memperbaiki program agar bisa memberikan lebih dari 1 jalur yang di rekomendasikan ke pengguna (user).

2. Dikembangkan pada perangkat mobile seperti di Android dan $i O S$ agar lebih mempermudah untuk di gunakan.

\section{DAFTAR PUSTAKA}

1. Syahputra, Siswan. (2017). Penentuan Rute Terpendek Pendistribusian Naskah Ujian

Nasional Menggunakan Algoritma Dijkstra (Dinas Pendidikan Dan Pengajaran Kota Binjai). Rute Terpendek, Algoritma Djikstra.

2. Sulistiani, Heni dan Danang Ari Wibowo. (2018). Perbandingan Algoritma A* Dan Dijsktra Dalam Pencarian Kecamatan Dan Kelurahan Di Bandar Lampung. Perbandingan Algoritma A* dan Algoritma Dijsktra.

3. Pratiarso, Aries dkk. (2010). Perbandingan Metode Ant Colony Optimization Dan Dijkstra Untuk Pengembangan Sistem Pengiriman Barang Di Kantor Pos Area Surabaya Timur Berbasis J2ME. Perbandingan Metode Ant Colony Optimization dan Algoritma Dijkstra.

4. Joni, Luh Erawati Dewi. (2010). Pencarian Rute Terpendek Tempat wisata Di Bali Dengan Menggunakan Algoritma Djikstra Rute Terpendek, Algoritma Djikstra.

5. Saputra, Ragil. (2011). Sistem Informasi Geografis Pencarian Rute Optimum Obyek Wisata Kota Yogyakarta Dengan Algoritma Floyd-Warshall. Sistem Informasi Geografis Pencarian Rute, Algoritma Floyd-Warshall.

6. Musabbichin, Laylul. Mula'ab., dan Rika Yunitarini. (2015). Sistem Informasi Geografis Penentuan Jalur Terpendek Untuk Menghindari Daerah Rawan Banjir (Studi Kasus Propinsi Jawa Timur).Sistem Informasi Geografis, Jalur Terpendek.

7. Syukriyah, Yenie. Falahah, dan Hermi Solihin. (2016). Penerapan Algoritma A* (Star) Untuk Mencari Rute Tercepat Dengan Hambatan. Algoritma A*, Rute Tercepat.

8. Juniawan, Panca Fransiskus. Dwi Yuny Sylfania., dan Eza Budi Perkasa. (2017). Pemanfaatan Algoritme A* Menggunakan Aispace Dalam Pencarian Rute Terpendek. Rute Terpendek, Algoritme A*.

9. Fatkhurrozi, Bagus dan Ika Setyowati. Pencarian Rute Terpendek Objek Wisata Di Magelang 
Menggunakan Ant Colony Optimization (Aco). Pencarian Rute Terpendek, Metode Ant Colony Optimization.

10. Andriani, Anik. (2014). Rancang Bangun Sistem Informasi Rute Wisata Terpendek Berbasis Algoritma Floyd-Warshall. Rancang Bangun Sistem Informasi Rute Wisata Terpendek, Algoritma Floyd-Warshall.

11. Aini, Anisah (2007). Artikel Mengenai Sistem Informasi Geografis Pengertian Dan Aplikasinya
12. Putri, W.R., 2012. Artikel Mengenai Pemrograman Web. Diambil dari:http://ilmukomputer.org/wpcontent/uploads/ 2012/10/windapemrograman-web. pdf . Diakses pada 7 Agustus 2018.

13. Rokhman, Moh Miftakhur. 2017. Sistem Informasi Geografi Pemetaan Sebaran Lokasi Fasilias Kesehatan Masyarakat Di Wilayah Kota Malang Berbasis Web. Pemetaan, SIG, Kesehatan. 